\title{
Informasi Spasial Pendugaan Potensi Ikan Pelagis Kecil di Perairan Tapanuli Tengah dan Sibolga
}

\section{Spatial Information on the Establishment of Small Pelagic Fish Potentials in the Tapanuli Tengah and Sibolga Waters}

\author{
Rosmasita $^{1 *}$, Bastian Putrayadi Silalahi ${ }^{1}$, Fitri Ariani ${ }^{1}$, Hensamuel Situmeang ${ }^{2}$, \\ dan Berliana Novita ${ }^{2}$ \\ ${ }^{\prime}$ Dosen Sekolah Tinggi Perikanan dan Kelautan Matauli \\ ${ }^{2}$ Mahasiswa Sekolah Tinggi Perikanan dan Kelautan Matauli \\ *Email: rosmasita@gmail.com
}

\begin{abstract}
Abstrak
Diterima

Kabupaten Tapanuli Tengah dan Kota Sibolga merupakan salah satu penghasil ikan

15 Mei 2020 pelagis kecil di perairan Barat Sumatera. Informasi spasial pendugaan potensi ikan pelagis kecil di Perairan Tapanuli Tengah dan Sibolga sangat diperlukan untuk mengetahui keberlangsungan ikan dan memudahkan nelayan menangkap ikan. Penelitian ini dilaksanakan pada bulan Februari-April 2020 dengan memanfaatkan

Disetujui data sekunder dari Dinas Perikanan dan Kelautan Provinsi Sumatera Utara tahun 29 Mei 20202010 - 2015 dalam penyusunan Rencana Zonasi Wilayah Pesisir dan Pulau-Pulau Kecil (RZWP3) tahun 2016. Hasil menunjukkan potensi ikan pelagis kecil yang ada di perairan Tapanuli Tengah dan Sibolga berjumlah 18 spesies dengan total volume dan nilai produksi yaitu: Kota Sibolga adalah 23.699,2 Ton (Rp.382,45 Milyar) dan Kabupaten Tapanuli Tengah sebesar 16.921,8 Ton (Rp. 254,37 Milyar). Pendugaan kelimpahan ikan di perairan Tapanuli Tengah tergolong sedang dan di perairan Sibolga tergolong Sedang dan Tinggi. Jenis ikan di perairan Tapanuli Tengah yaitu: Kembung, Selar Komo, Teri dan Belanak. Sedangkan di perairan Sibolga jenis ikan yang tergolong memiliki kelimpahan tinggi yaitu ikan Teri, Layang dan Japuh sedangkan ikan Kembung dan Selar Komo tergolong sedang.
\end{abstract}

Kata kunci: Potensi ikan, Tapanuli Tengah, Sibolga, Ikan Pelagis Kecil.

\begin{abstract}
Tapanuli Tengah and Sibolga are one of the producers of small pelagic fish in the waters of West Sumatera. Spatial information on estimating the potential of small pelagic fish in the waters of Central Tapanuli and Sibolga is needed to determine the sustainability of the fish and make it easier for fishermen to catch fish. This research was conducted in February-April 2020 by utilizing secondary data from the North Sumatra Province Fisheries and Maritime Service in 2010 - 2015 in the preparation of the Coastal and Small Islands Zoning Plan (RZWP3) in 2016. The result showed the potential of small pelagic fish that exist in Tapanuli Tengah and Sibolga waters there are 18 species with a total volume and value of production, namely: Sibolga is 23,699.2 Tons (Rp.382.45 Billion) and Tapanuli Tengah is 16,921.8 Tons (Rp. 254.37 Billion). Estimation of fish abundance in Tapanuli Tengah and Sibolga waters are classified in Medium and High. The types of fish in Tapanuli Tengah waters are: Restrelinger spp, Selaroides leptolepis, stolephorus commersonii and Mugil Sp. Whereas in Sibolga waters the types of fish that are classified as having high abundance are Stolephorus commersonii, Decapterus ruselli and Dussumieria spp, while Restrelinger spp and Selaroides leptolepis classified is medium.
\end{abstract}

Keyword: Potential fish, Sibolga, Small Pelagic Fish, Tapanuli Tengah 


\section{Pendahuluan}

Kabupaten Tapanuli Tengah dan Kota Sibolga merupakan salah satu penghasil ikan pelagis kecil di perairan Barat Sumatera. Ikan pelagis kecil adalah kelompok besar ikan yang membentuk (Brehmer et al. 2007; D'Elia et al. 2009) di dalam kehidupannya dan mempunyai sifat berenang bebas dengan melakukan migrasi secara vertikal maupun horizontal mendekati permukaan dengan ukuran tubuh relatif kecil (Widodo et al. 1994; Fréon et al. 2005). Ikan pelagis umumnya senang bergerombol, baik dengan kelompoknya maupun dengan jenis ikan lainnya. Ikan pelagis kecil bersifat fototaksis positif (tertarik pada cahaya) dan tertarik benda-benda yang terapung. Ikan pelagis kecil cenderung bergerombol berdasarkan kelompok ukuran (Amin et al. 2014). Kebiasaan makan ikan pelagis umumnya waktu matahari terbit dan saat matahari terbenam dan termasuk pemakan plankton, baik plankton nabati maupun plankton hewani (Izzani 2012). Ikan pelagis kecil merupakan elemen yang penting dalam ekosistem laut karena biomassa yang signifikan pada level menengah dari jaring makanan, sehingga memegang peranan penting menghubungkan tingkatan trofik atas dan bawah dalam struktur trofik (Bakun 1996, Cury et al. 2000; Fréon et al. 2005; Palomera et al. 2007; Peltonen et al. 2007).

Saat ini informasi potensi ikan dapat diketahui setelah didaratkan di pelabuhan atau di Tempat Pendaratan Ikan (TPI) yang disediakan, namun untuk informasi spasialnya sering menjadi kendala karena nelayan yang menangkap ikan di laut jarang sekali mau memberikan informasi dimana lokasi/ daerah menangkap ikan. Informasi spasial potensi ikan pelagis kecil di perairan Tapanuli Tengah dan Sibolga sangat diperlukan untuk keberlangsungan keberadaan ikan pelagis dan sebagai informasi untuk manajemen ikan pelagis. Survei lapangan dengan teknik konvensional akan memakan waktu yang lama dan biaya yang mahal, maka pemanfaatan Sistem Informasi Geografis (SIG) hadir sebagai solusinya.

Pemetaan potensi ikan telah banyak dilakukan oleh peneliti sebelumnya, seperti Mayu et al (2018) analisis potensi dan tingkat pemanfaatan sumberdaya ikan di perairan Kabupaten Bangka Selatan; Murniati (2011) tentang potensi dan tingkat pemanfaatan ikan terbang (Exocoetidae) di Perairan Majene, Kabupaten Majene Provinsi Sulawesi Barat; Noija et al (2014) tentang potensi dan tingkat pemanfaatan sumberdaya ikan demersal di perairan Pulau Ambon - Provinsi Maluku; Cahyani et al (2013) tentang potensi lestari sumberdaya ikan demersal (analisis hasil tangkapan cantrang yang didaratkan di TPI Wedung Demak; Nugraha et al (2012) tentang potensi lestari dan tingkat pemanfaatan ikan kurisi (Nemipterus Japonicus) di Perairan Teluk Banten; namun di perairan Tapanuli Tengah dan Sibolga belum ada yang melakukannya.

Berdasarkan uraian tersebut, maka penelitian ini bertujuan untuk memberikan informasi spasial tentang pendugaan potensi ikan pelagis kecil di perairan Tapanuli Tengah dan Sibolga.

\section{Bahan dan Metode}

\subsection{Waktu dan Tempat}

Penelitian ini dilaksanakan pada bulan Februari-April 2020 dengan memanfaatkan data dari Dinas Perikanan dan Kelautan Provinsi Sumatera Utara dalam penyusunan Rencana Zonasi Wilayah Pesisir dan PulauPulau Kecil (RZWP3) dilaksanakan pada tahun 2015. Pengambilan data sampel dilakukan pada 31 stasiun pengamatan di Perairan Tapanuli Tengah dan Sibolga (Gambar 1).

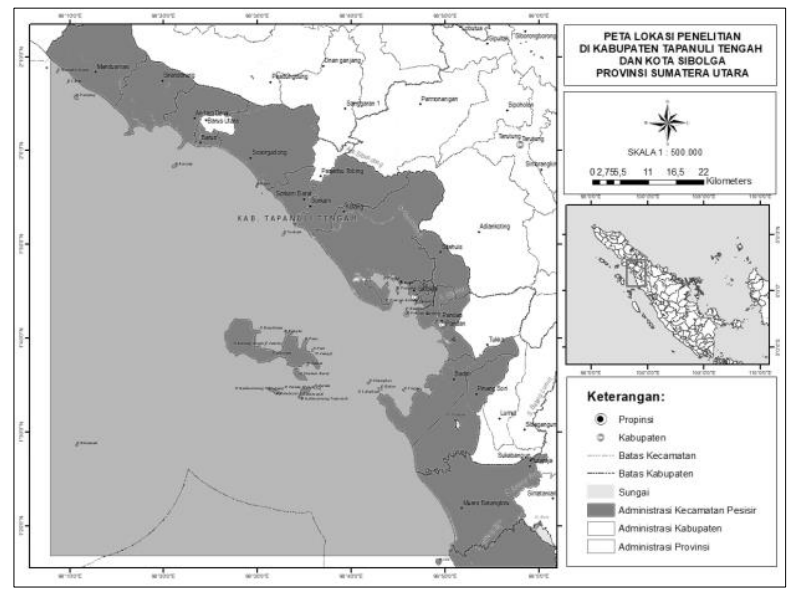

Gambar 1. Lokasi Penelitian 


\subsection{Alat dan Bahan}

Peralatan dalam penelitian ini dapat dikategorikan dalam peruntukan pengolahan data, terdiri dari seperangkat komputer dengan spesifikasi: Intel Core i3-500SU, 2.0 Hz, Random Access Memory (RAM) 4 GB, HDD 500 GB yang dilengkapi dengan aplikasi Microsoft Office dan image processing. Sedangkan bahan yang digunakan yaitu data perikanan tangkap dari Dinas Perikanan dan Kelautan Provinsi Sumatera tahun 2010 2015 dan data potensi ikan pelagis kecil dari Dinas Perikanan dan Kelautan Provinsi Sumatera Utara dalam penyusunan Rencana Zonasi Wilayah Pesisir dan Pulau-Pulau Kecil (RZWP3).

\subsection{Analisa Data}

Data yang diperoleh dihitung menggunakan analisis kuantitatif dan analisis deskriptif. Adapun metode analisis data yang digunakan disajikan pada Tabel 1 .

Tabel 1. Kebutuhan data, uraian dan analisis data

\begin{tabular}{|c|c|c|}
\hline Uraian & Analisis & Kebutuhan Data \\
\hline Produksi & Tren CPUE=a-bf & Produksi perikanan tangkap \\
\hline Pemilihan Komoditas & analisis Location Quotient (LQ) & produksi perikanan tangkap di Kabupaten Tapanuli \\
\hline Unggulan & 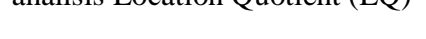 & Tengah dan Sibolga \\
\hline $\begin{array}{l}\text { Pola Operasi } \\
\text { penangkapan Ikan }\end{array}$ & Deskriptif & $\begin{array}{l}\text { kebutuhan Melaut, aktivitas penangkapan dan } \\
\text { teknologi penangkapan yang digunakan }\end{array}$ \\
\hline Musim Ikan & Deskriptif & wawancara;data tangkapan \\
\hline Fishing Ground & Pemetaan & Posisi Geografis Penangkapan tahun 2015 \\
\hline
\end{tabular}

\section{Hasil dan Pembahasan}

\subsection{Potensi dan Tingkat Pemanfaatan Perikanan Tangkap bagian Perairan Barat Sumatera, Sumatera Utara}

Pemanfaatan di Wilayah Perairan Barat Sumatera dari tahun 2010 hingga 2014 masih kurang tereksploitasi namun terjadi peningkatan pemanfaatan di tahun 2015. Melihat pemanfaatan sumberdaya ikan yang masih dapat ditingkatkan terdapat potensi sumberdaya ikan yang ada di Sumatera Utara yang masih dapat dimanfaatkan (Tabel 2).

Tabel 2. Potensi dan Tingkat Pemanfaatan Perikanan Tangkap bagian perairan Barat Sumatera, Sumatera Utara

\begin{tabular}{crrrc}
\hline Tahun & Potensi (Ton) & JTB (Ton) & Produksi & Tingkat Pemanfaatan \\
\hline 2010 & $565.200,00$ & $452.160,00$ & $125.123,09$ & 0,28 \\
2011 & $565.200,00$ & $452.160,00$ & $132.391,40$ & 0,29 \\
2012 & $565.200,00$ & $452.160,00$ & $168.537,54$ & 0,37 \\
2013 & $565.200,00$ & $452.160,00$ & $142.015,98$ & 0,31 \\
2014 & $565.200,00$ & $452.160,00$ & $133.859,27$ & 0,30 \\
2015 & $565.200,00$ & $452.160,00$ & $382.524,85$ & 0,85 \\
\hline
\end{tabular}

Sumber: Statistik Perikanan Tangkap Sumatera Utara dan Kepmen KP 2016

Keterangan Tingkat pemanfaatan (E):

$\mathrm{E}<0.5=$ Moderate, upaya penangkapan dapat ditambah;

$0.5 \leq \mathrm{E}<1=$ Fully-exploited, upaya penangkapan dipertahankan dengan monitor ketat

$\mathrm{E} \geq 1$ = Over-exploited, upaya penangkapan harus dikurangi

Potensi hasil perikanan tangkap di Provinsi Sumatera Utara (Sumut), per tahun mencapai 832.000 ton. Jumlah tersebut merupakan hasil tangkap perikanan yang berasal dari pantai barat dan pantai timur. Hasil perikanan tangkap yang dapat diperoleh dari pantai barat, jumlahnya jauh lebih besar ketimbang dari pantai timur. Di pantai timur potensinya sebesar 276.000 ton, sedangkan di pantai barat potensinya mencapai 556.000 to, hal ini dikarenakan kondisi laut yang terdapat di pantai barat jauh lebih luas dan lebih dalam dari perairan yang dimiliki pantai timur. Sehingga biota laut yang dapat hidup didalamnya pun jumlahnya jauh lebih besar. Selain itu, untuk di pantai barat tingkat kerusakan lautnya juga lebih rendah ketimbang di pantai timur (DKP Sumut 2015).

\subsection{Potensi Ikan Pelagis Kecil}

Hasil yang diperoleh dari data sekunder menunjukkan potensi ikan pelagis kecil yang ada di perairan Tapanuli Tengah dan Sibolga berjumlah 18 spesies dengan total volume dan nilai produksi yaitu: Kota Sibolga adalah 23.699,2 Ton (Rp.382,45 Milyar) dan Kabupaten Tapanuli Tengah sebesar 16.921,8 Ton (Rp. 254,37 
Milyar) (Dinas Kelautan dan Perikanan Provinsi Sumatera Utara, 2016). Volume dan nilai produksi perikanan tangkap ikan pelagis kecil Provinsi Sumatera Utara berdasarkan jenis ikan pelagis kecil disajikan pada Tabel 3.

Tabel 3. Volume dan Nilai Produksi Perikanan Tangkap Ikan Pelagis Kecil Provinsi Sumatera Utara Berdasarkan Jenis Ikan Pelagis Kecil

\begin{tabular}{|c|c|c|c|c|c|}
\hline \multirow{3}{*}{ No } & \multirow{3}{*}{ Jenis ikan Pelagis } & \multicolumn{4}{|c|}{ Kabupaten/Kota } \\
\hline & & \multicolumn{2}{|c|}{ Tapanuli Tengah } & \multicolumn{2}{|c|}{ Sibolga } \\
\hline & & Ton & $\mathrm{Rp}$ & Ton & $\mathrm{Rp}$ \\
\hline 1 & Teri & 1924,8 & 34.646 .400 & 6299,9 & 100.797 .830 \\
\hline 2 & Belanak & 1418,6 & 17.023 .200 & 335,7 & 6.479 .261 \\
\hline 3 & Bentong & 1566,4 & 25.845 .600 & - & - \\
\hline 4 & Cendro & - & - & 57,7 & 771.763 \\
\hline 5 & Talang-talang & 574,1 & 6.315 .100 & 713,4 & 11.949 .686 \\
\hline 6 & Terbang & 46 & 552.000 & - & - \\
\hline 7 & Tapuh & 153,6 & 1.992 .900 & 1316,6 & 11.191 .308 \\
\hline 8 & Julung-Julung & 657,4 & 5.259 .200 & - & - \\
\hline 9 & Banyar & - & - & 1300,9 & 7.805 .327 \\
\hline 10 & Kembung & 2792,9 & 51.058 .500 & 2323,8 & 45.545 .764 \\
\hline 11 & Layang anggur & - & - & 5266,5 & 100.063 .458 \\
\hline 12 & Layang deles & 3774,3 & 52.647 .400 & - & - \\
\hline 13 & Siro & - & - & 263,7 & 3.691 .800 \\
\hline 14 & Selar komo & - & - & 1718,5 & 30.803 .900 \\
\hline 15 & Selar kuning & 36,5 & 984.500 & - & - \\
\hline 16 & Sunglir & - & - & 369,8 & 4.437 .600 \\
\hline 17 & Tembang & - & - & 575,5 & 5.179 .500 \\
\hline 18 & Tetengkek & - & - & 778,6 & 2.457 .600 \\
\hline 19 & Ikan pelagis lainnya & 10,2 & 255.000 & 307,6 & 2.460 .960 \\
\hline
\end{tabular}

Jenis ikan pelagis kecil yang paling dominan (Gambar 2) yaitu ikan Teri untuk Sibolga sebesar 6.299,9 ton, Layang anggur sebesar 5.266,5 Ton, Kembung sebesar 2.323,8 Ton dan Selar komo sebesar 1.718,5 ton. Sedangkan untuk Tapanuli Tengah yaitu ikan Teri sebesar 1.924,8 Ton, Belanak sebesar 1.418,6 Ton, Bentong sebesar 1.566,4 Ton, Kembung sebesar 2.792,9 Ton dan Layang ledes sebesar 3.774,3 Ton.

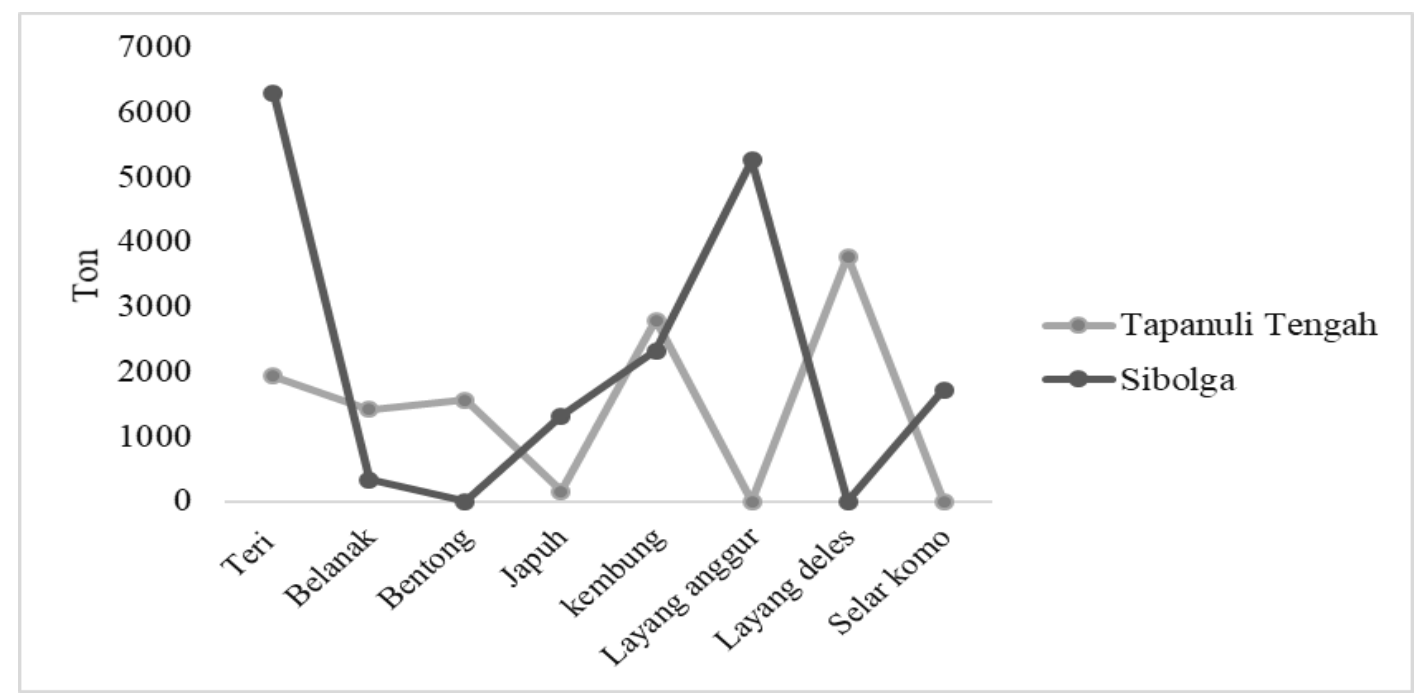

Gambar 2. Ikan Pelagis Kecil Dominan di Perairan Sibolga dan Tapanuli Tengah

\subsection{Potensi Ikan Pelagis Kecil di Perairan Tapanuli Tengah dan Sibolga}

Berdasarkan analisis kualitatif, potensi kelimpahan ikan di perairan Tapanuli Tengah dan Sibolga pada tahun 2015 tergolong menjadi dua kelas yaitu sedang dan tinggi (Gambar 3). Di perairan Sibolga terdapat 5 jenis ikan yang memiliki kelimpahan tinggi dan sedang. Jenis ikan yang tergolong memiliki kelimpahan tinggi yaitu ikan Teri, Layang dan Japuh sedangkan ikan Kembung dan Selar Komo tergolong sedang. Sedangkan di perairan Tapanuli Tengah terdapat 4 jenis ikan yang memiliki kelimpahan sedang yaitu: Kembung, Selar Komo, Teri dan Belanak (Tabel 4). 
Tabel 4. Kelimpahan dan Jenis Ikan Pelagis Kecil di Perairan Tapanuli Tengah dan Sibolga

\begin{tabular}{|c|c|c|c|c|c|}
\hline No & Kabupaten/Kota & Tangkapan & Kelimpahan & Lintang & Bujur \\
\hline \multirow{16}{*}{1} & \multirow{16}{*}{ Tapanuli Tengah } & Kembung & Sedang & 98,3174 & 1,9220 \\
\hline & & Selar Komo & Sedang & 98,5071 & 1,5470 \\
\hline & & Teri & Sedang & 98,4795 & 1,7362 \\
\hline & & Kembung & Sedang & 98,1198 & 2,0544 \\
\hline & & Teri & Sedang & 98,5674 & 1,4677 \\
\hline & & Selar Komo & Sedang & 98,4771 & 1,5760 \\
\hline & & Teri & Sedang & 98,0870 & 2,0912 \\
\hline & & Belanak & Sedang & 98,0950 & 2,1931 \\
\hline & & Teri & Sedang & 98,5765 & 1,8022 \\
\hline & & Teri & Sedang & 98,4025 & 1,9496 \\
\hline & & Kembung & Sedang & 98,4065 & 1,8977 \\
\hline & & Kembung & Sedang & 98,2137 & 1,9472 \\
\hline & & Kembung & Sedang & 98,3550 & 1,6822 \\
\hline & & Belanak & Sedang & 98,5118 & 1,9036 \\
\hline & & Selar Komo & Sedang & 98,4053 & 1,7036 \\
\hline & & Belanak & Sedang & 98,1857 & 2,0293 \\
\hline \multirow{15}{*}{2} & \multirow{15}{*}{ Sibolga } & Layang & Tinggi & 98,6757 & 1,6322 \\
\hline & & Layang & Tinggi & 98,6757 & 1,6322 \\
\hline & & Layang & Tinggi & 98,6891 & 1,6294 \\
\hline & & Japuh & Tinggi & 98,7262 & 1,5818 \\
\hline & & Teri & Tinggi & 98,7538 & 1,6869 \\
\hline & & Teri & Tinggi & 98,7566 & 1,6316 \\
\hline & & Teri & Tinggi & 98,7957 & 1,6654 \\
\hline & & Kembung & Sedang & 98,7695 & 1,6018 \\
\hline & & Kembung & Sedang & 98,6738 & 1,5913 \\
\hline & & Kembung & Sedang & 98,6672 & 1,7179 \\
\hline & & Kembung & Sedang & 98,6089 & 1,7524 \\
\hline & & Kembung & Sedang & 98,6040 & 1,5336 \\
\hline & & Teri & Tinggi & 98,7846 & 1,6414 \\
\hline & & Selar Komo & Sedang & 98,5258 & 1,6968 \\
\hline & & Selar Komo & Sedang & 98,5991 & 1,6563 \\
\hline
\end{tabular}

Hasil interpolasi menunjukkan sebaran kelimpahan ikan pelagis kecil di perairan Tapanuli Tengah dan Sibolga masih tergolong baik. Berdasarkan hal tersebut, pemanfaatan ikan pelagis di wilayah ini dapat masih dapat ditingkatkan dan diharapkan dapat meningkatkan perekonomian masyarakat, khususnya masyarakat pesisir.

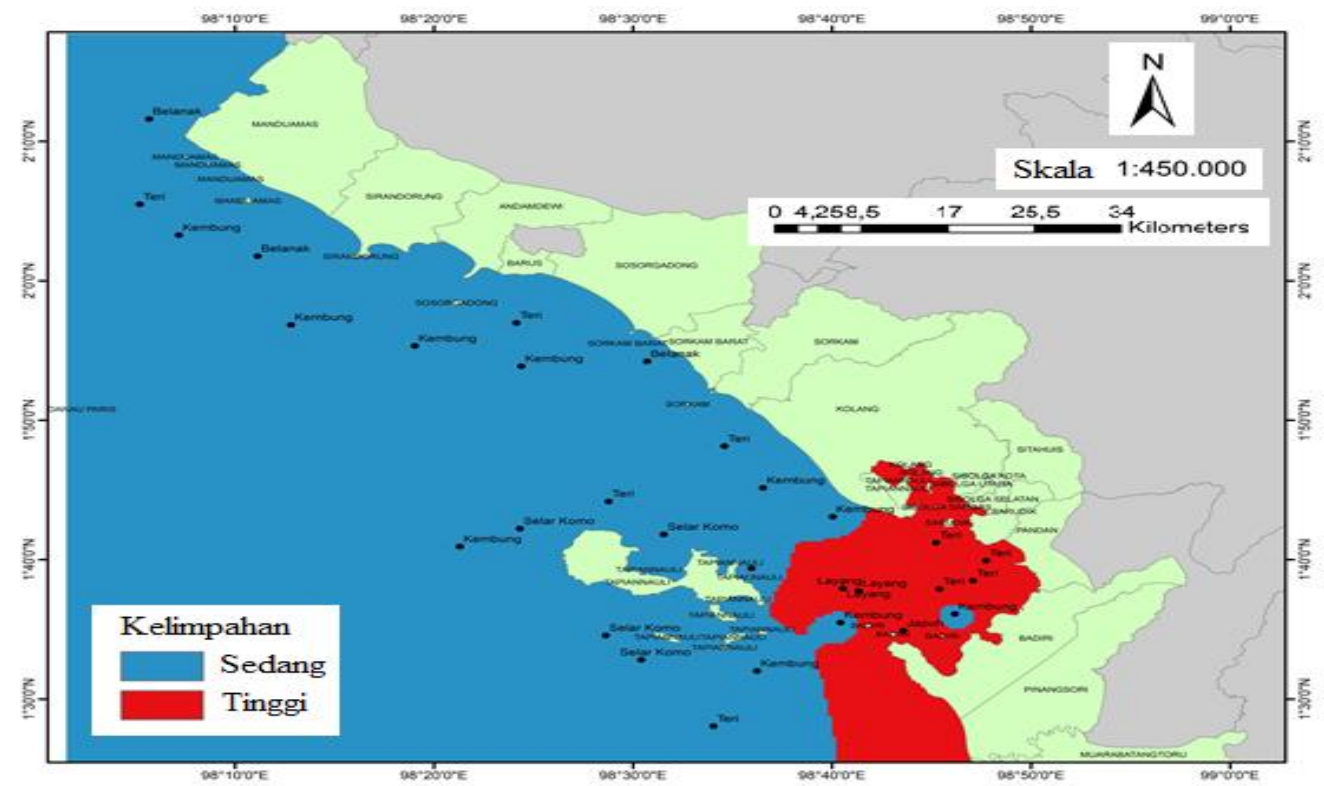

Gambar 3. Peta Potensi Kelimpahan Ikan Pelagis Kecil di Perairan Tapanuli Tengah 


\section{Kesimpulan}

Potensi ikan pelagis kecil yang ada di perairan Tapanuli Tengah dan Sibolga berjumlah 18 spesies dengan total volume dan nilai produksi yaitu: Kota Sibolga adalah 23.699,2 Ton (Rp.382,45 Milyar) dan Kabupaten Tapanuli Tengah sebesar 16.921,8 Ton (Rp. 254,37 Milyar). Pendugaan kelimpahan ikan di perairan Tapanuli Tengah tergolong sedang dan di perairan Sibolga tergolong Sedang dan Tinggi. Jenis ikan di perairan Tapanuli Tengah yaitu: Kembung, Selar Komo, Teri dan Belanak. Sedangkan di perairan Sibolga jenis ikan yang tergolong memiliki kelimpahan tinggi yaitu ikan Teri, Layang dan Japuh sedangkan ikan Kembung dan Selar Komo tergolong sedang.

\section{Saran}

Diperlukannya penelitian lanjutan tentang potensi ikan pelagis kecil di perairan Tapanuli Tengah dan Sibolga tahun 2016-2020, kemudian dilakukannya prediksi potensi ikan pelagis kecil di perairan Tapanuli Tengah dan Sibolga untuk melihat keberlangsungan keberadaan ikan dan dihubungkannya dengan parameter oseanografi perairan.

\section{Ucapan Terimakasih}

Penulis mengucapkan terimakasih yang sebesar-besarnya kepada Dinas Perikanan dan Kelautan Provinsi Sumatera Utara sebagai penyedia data yang digunakan dalam penelitian ini.

\section{Referensi}

Amin, S.M.N., M.M.K. Azim, S.N.J. Fatinah, A. Arshad, M.A. Rahman, and K.C.A. Jalal. 2014. Population Parameters of Rastrelliger kanagurta (Cuvier, 1816) in The Marudu Bay, Sabah, Malaysia. Iranian Journal of Fisheries Sciences. Vol (2): 262-275

Brehmer, P., Gerlotto, F., Laurent, C., Cotel, P., Achury, A and Samb, B. 2007. Schooling behaviour of small pelagic fish: phenotypic expression of independent stimuli. Journal Marine Ecology Progress Series, Vol. 334: 263-272.

D’Elia, M., B. Patti, A. Sulli, G. Tranchida, A. Bonanno, G. Basilone, G. Giacalone, I. Fontana, S. Genovese, C. Guisande, and M. Mazzola. 2009. Distribution and spatial structure of pelagic fish schools in relation to the nature of the seabed in the Sicily Straits (Central Mediterranean). Journal Marine Ecology Series, Vol 1: 151-160.

Fréon P, Cury P, Shannon L, Roy C. 2005. Sustainable Exploitation of Small Pelagic Fish Stocks Challenged by Environmental and Ecosystem Changes: A Review. Bulletin of Marine Science, LXXVI (2): 385-462.

Izzani N. 2012. Kebiasaan Makanan Ikan Tembang (Sardinella fimbriata Cuvier and Valenciennes 1847) dari Perairan Selat Sunda yang Didaratkan di PPP Labuan, Kabupaten Pandeglang, Banten [Skripsi]. Institut Pertanian Bogor. Bogor.

Mayua, H, M., Kurniawan dan Febrianto, A. 2018. Analisis Potensi dan Tingkat Pemanfaatan Sumberdaya Ikan di Perairan Kabupaten Bangka Selatan. Jurnal Perikanan Tangkap, 2(1): 30-41.

Murniati. 2011. Potensi dan Tingkat Pemanfaatan Ikan Terbang (Exocoetidae) Di Perairan Majene, Kabupaten Majene Provinsi Sulawesi Barat. [Skripsi]. Universitas Hasanuddin. Makassar . 52 hlm

Noija, D., S. Martasuganda, B. Murdiyanto, dan A.A. Taurusman. 2014. Potensi dan Tingkat Pemanfaatan Sumberdaya Ikan Demersal di Perairan Pulau Ambon - Provinsi Maluku. Jurnal Teknologi Perikanan dan Kelautan. 5(1): 55-64.

Nugraha, E. Koswara, B. dan Yuniarti. 2012. Potensi Lestari Dan Tingkat Pemanfaatan Ikan Kurisi (Nemipterus Japonicus) Di Perairan Teluk Banten. Jurnal Perikanan dan Kelautan. 3(1): 91-98.

Peltonen, H., L. Miska, J.P. Pääkkönen, M. Karjalainen, A. Tuomaala, J. Pönni, and M. Viitasalo. 2007. Pelagic Fish Abundance in Relation to Regional Environmental Variation in The Gulf of Finland, Northern Baltic Sea. ICES Journal of Marine Science LXIV (3): 487-495.

Widodo, J. 1997. Review of The Small Pelagic Fisheries of Indonesia. Small Pelagic Resources and Their Fisheries in The Asia-Pacific region. Proceeding of The APFIC Working Party on Marine Fisheries, First Session, 13-16 May 1997, Bangkok, Thailand. RAP Publication 1997/31. p199-226. 